\title{
Flipped Classroom Strategy and Nigerian Educational System: Issues, Problems and Prospects
}

\author{
Olatunbosun, Segun Mobolaji (Ph.D) \\ Department of Science Education, Faculty of Education, Ekiti State University, Ado Ekiti, Nigeria \\ Ogunyebi, Tunji Henry \\ Department of Integrated Science, College of Education, Ikere Ekiti, Nigeria
}

\begin{abstract}
This paper examined the flippedclassroom strategy as a method in the teaching-learning process in the Nigerian educational system. Issues, problems and the prospectsof flipped classroom strategy on junior secondary school students' performance was also examined in science class specifically. The study adopted a quasi-experimental pre-test, post-test, control group design. Four null hypotheses were generated and tested at 0.05 level of significance. The sample consisted of 120 junior secondary school II Basic Science students selected through multistage random sampling technique. The instrument that was used for the study was Basic Science Achievement Test (BSAT). It is a self-designed instrument that consisted of information on bio-data of the respondents and 40 multiple-choice items. The data were analyzed using inferential statistics of t-test. The study found out that there was a significant difference between the posttest means scores of students exposed to flipped classroom strategy and conventional strategies. It was also revealed in the study that there was no significant difference between the posttest means scores of male and female students exposed to flipped classroom strategy and conventional strategies. Based on this finding, it was recommended among other things that the Nigerian government should organize a seminar among the teachers in secondary schools in each state on the effective use of flipped classroom strategy in their various classes to enhance performance.
\end{abstract}

Keywords- Flipped classroom strategy, Performance, issues, prospects, educational system

DOI: $10.7176 / \mathrm{JEP} / 10-20-06$

Publication date:July $31^{\text {st }} 2019$

\section{Introduction}

Nigeria today is undergoing major transformations which are multidimensional, affecting the technological, economic, social, cultural and political development of human communities. Education in the generic and global context is a strategic instrument for technological and economic transformation. The focus of education system all over the world is the development of the human capital required to meet present and future challenges of globalization (Dike, 2014). The enviable position of Science education system of most countries of the world, including Nigeria is perhaps justifiable. The reason is that science can exert a dominant influence of life of individual as well as on the developmental effort of a nation. The Universal recognition of the above submission is responsible for the prime position that has accorded science and in particular Basic Science which serves as a pivot upon which other sciences rotate. The importance of Basic Science cannot be over stressed. All students must learn and pass it at the Junior Secondary School level before they can advance to the senior level.Despite the importance of Basic Science to mankind and the efforts of researchers to improve on its teaching and learning, the performance of students in the subject is still not encouraging. The rate and degree of failure could not be specifically determined but may be as a result of factors like teacher's qualification, school environment, teaching strategies among others(Adu \& Adeyanju, 2013).

Research evidences have proved that Science contributes to the quality of life and nation building in all aspects of human endeavour (Abimbola, 2013). Therefore, for any meaningful development to take place, every nation must embark on knowledge and skills of science and technology for rapid and sustainable social, economic, political and technological advancement. Teachers' teaching strategies plays a significant role towards improve teaching and learning process. Student-centred approach supported by educational media could enhance effective teaching and learning. Among the new educational media for teaching and learning is flipped classroom instructional practice.

A flipped classroom is an instructional strategy and a type of blended learning that reverses the traditional learning environment by delivering instructional content, often online, outside of the classroom. It is one such learning strategy that creates learning through technology, especially online video media, which helps reduce lecture time and increase the time for in-class activities where learners can learn cooperatively through practice (DeLozier\&Rhodes, 2017). Technology can support flipped classrooms by letting students gain first by exposure to new material outside of class, usually via reading or lecture videos and then using class time to do the harder work of assimilating that knowledge, perhaps through problemsolving, discussion, or debates. The growing accessibility and sophistication of educational technologies opens up increasing possibilities for students to 
explore, share, andcreate content (Bergmann \&Sams, 2012). In addition, a flipped classroom has also been shown to promote not only students' sense of responsibility for their own work and self-regulation in assignment submission, but also their responsibility toward group assignments and classroomactivities (Panich, 2013; Yilmaz, 2017).

Flipped classroom instructional practice, is a new model for effective teaching. Leo and Puzio (2016) referred to it as a form of blended learning in which learners learn content online by listening to audio lectures or watching the video lectures, mostly at their various home, and assignment is done together in the class with teachersand students discussing and solving questions. Students can work together on a task, exchange their opinion, experiences, views, discuss and negotiate strategies, actions and results through flipped classroom. These actions can provide students with opportunity to help, discuss, review, teach, influence each other and thereby enhance a motivational situation for developing a learning community. In flipped classroom, teacher's role is of a mentoror facilitator of the learning process. The achievements of individual memberwithin the group are shared among the group members ( Zhonggen and Guifang, 2016).

There are a lot of studies on learning styles that encourage presenting student-based activities and participationin discussion allowing students to effectively control the content, organize effective experiences, think creatively,reinforce cognitive development and improve their academic performance. In addition, the heavy theoretical andapplied support for knowledge benefits and motivation for cooperation is increasing unlike the competitive andindividual learning activities irrespective of gender (Jarvenoja, 2010).Cooperative learning encourages students to divide teamwork, employ individual contributions and reinforcemeta-cognition by providing several chances of communication between learners (Songhao, 2011). Therefore,the developed countries adopt new learning and teaching strategies supported by the rapid development of information and communication technology and the students' spreading use of electronic devices by spending alot of time on electronic games, e-mails, internet and cell phones. All these devices became an integral part ofstudents' lives and hence it is important to find evidences on how to make electronic learning a strong motivatorfor change, how to redesign the educational systems, and how to depend on the internet to reinforce theclassroom experience. The model of student-centered flipped classroom leads to digesting thecurricula and mastering the skills according to the lower level of the cognitive domain in Bloom's Taxonomy(Knowledge and Comprehension) at home. It also leads to focusing on the higher level of cognitive domain(Application, Analysis, Synthesis and Evaluation) in the classroom time (Songhao, 2011).

This model of flipped classroom is designed to improve students' motivation since it promotes competence,independence and self-motivations. The flipped classroom strategy is probably designed to address the students'needs of self-efficacy and competence through an integrated system. According to studies conducted in the lasttwo decades, students feel self-effective when they participate actively in spreading knowledge unlike what they have previously been when receiving knowledge from the instructor through traditional teaching (Abey,2015).In addition, flipped classrooms contribute to encouraging and improving skills in the domains of application, analysis, synthesis and evaluation which are all mental skills and processes not covered by the traditionalcurricula. It also contributes to what is known as ownership for learning, where students can watcha video or lecture several times. This model led to building the confidence and enjoying the content and it provided more chances for interaction, learning, positive change and responsibility towards education (Mok, 2014). The flipped classroom strategy integrates two learning theories; i.e. traditional learning and activelearning, being based mainly on flipping the learning process where students receive the lesson's new concepts at home through 5-10 minutes video clips or social media networks by modern technologies such as smart phones and laptops (Bishop, 2013)

\section{FLIPPED CLASSROOM ISSUES, PROBLEMS AND PROSPECTS}

Media and internet technology has given students and teachers actual educational restructuring that develops learning skills. Academic administrators and teachers must appreciate information technology in a students' education. Consequently, the learning and teaching process has become accessible and flexible enough with internet communication technology, whether by providing multimedia content or educational assessment for teachers and students. The availability of different multimedia services including Teacher-Tube, Google, Smart board, Magic board, Slides share, Smart phones, YouTube, and other significant media accessories indicate that the educational process will develop rapidly and become an automated field where students feel self-sufficiency (Collins \& Halverson, 2009). Harris (2016) conclude that "the flipped classroom model is one model thateducators are experimenting in order to address the needs of learners and expand students ${ }^{\text {ee }}$ capabilities for learning more efficiently and effectively in a time when lifelong learning is crucial to individuals and society."

In order for students to experience success, the Flipped Classroom method requires that students first complete their assigned readings and carefully review the preparatory material (video lectures) prior to attending class (Fulton, 2012. Only then can the students' learning be maximizedduring in-class time because the topics covered often build upon one another incrementally and course examinations are heavily dependent on higher 
order thinking and reasoning skills.

In this study, the overall effectiveness of the Flipped Classroom method of teaching was rated high by students because students are able to work at their own pace while in-class, there is more time to practice and collaboratively participate. In general, students felt they were given a greater number of opportunities to be actively engaged in their own learning and progressively improve their mastery over the course content.

\section{Challenges and problems}

Despite flipped classroom effectiveness, there are group presentations where some students have problems with the fact that individual members in any given group were not held accountable for their degree of involvement/contribution because the final mark was a collective group mark. Some students maysuggest incorporating an evaluation measure for theirindividual team members in order to allow for increased accountability. In other cases, students comment thatthey don't particularly enjoy the group presentations becausepresenting was considered to be an "uncomfortable" and in some instances a "frightening" experience.

Another noteworthy finding was based on the fact that some students reported the video lectures to be limited in several technological aspects. Some of the videos were found to be of poor audio quality, too long in duration, and did not allow for immediate feedback. These findingsare not surprising as previous studies have also highlighted the limitations of technology as an important factor in determining the student experience in the Flipped Classroom (Strayer, 2012).

The main challenges that arose from using the Flipped Classroom approach in a graduate level setting were twofold and included issues due to student comfort level and use of technology. While managing technology was a big issue in our administration of the Flipped Classroom, another equally important aspect of this teaching model is the need to ensure that students are actually stimulated in class and find the learning environment to be safe (withoutdiscomfort and fear), supportive and beneficial to their learning.

On the technology front, students found the audio quality of certain videos to be poor. On those occasions, it made it difficult for students to clearly hear the instructor irrespective of how high they adjusted their audio settings. They also commented on how some of the video lectures had background noise, which made it difficult for them to easily follow along and fully comprehend the concepts being explained by the instructor. In other instances, studentswere not pleased with administrative processes that resulted in the delay by a few days of the release time of certain videos. They felt that the lack of timely distribution of the video lectures did not allow them sufficient time to adequately prepare for the quizzes and the in-class practice problems, which were issued on a weekly basis.

Moreover, when they did view the video lectures at home, some students expressed dissatisfaction with the fact that they could not ask questions of the instructor in real-time. The instructor had recommended to students to record their questions during their viewing of the video and bring them to the next tutorial session and/or class as an item for discussion but some students felt that the lag in time did not appropriately facilitate their learning. Also, a few students stated that by the time they arrived to the tutorial session and/or the class, they had forgotten whichareas they had difficulties understanding in the videos.

The final concern expressed by some students was the fact that the video lectures were often over an hour long in length, which made it difficult for them to view them in a single seating. Further complicating this issue was the fact that on those occasions when students decided to pause the video and return to it a short time later, many experienced technical difficulties. They were unable to recommence viewing the video from the point where they had previously paused it since the video location had returned to its original starting point.

Further, it requires a motivated teacher who has the will to followupstudents' progress. This requires providing additional working hours and effortfrom teachers. Furthermore, teachers should be professional in integrating moderntechnological in education. Therefore, implementing this strategy could be difficultfor educators who are not qualified in using technology or communication skills.Some obstacles may face the educational and learning process while applyingtechnology tools in the classroom. These obstacles include: 1) the lack of devices andsoftware used in recording and preparing lessons, 2) the lack of teachers' skills in using the technology tools skillfully to develop teaching methods, motivation andcommunicating with students, 3) the insistence of teachers to follow the traditionalmethod in their teaching process. However, those teachers can be convinced throughpresenting successful practices of applying technology in the classroom comparingwith the traditional method (Deslaurier, 2011).

\section{Positives and prospects of flipped classroom}

According to Strohmyer (2016) applying flipped classroom strategy achieves many benefits. These benefits include that flipped classroom: 1) guarantees for teacher making good use of classroom period; so, he/she makes use of time in guiding and helping, 2) enhances the critical thinking, self- learning, building experiences, communication skills, and cooperation among students, 3) provides a technique to evaluate the students' understanding because tests and short tasks that students perform are indicators of weaknesses and strengths in 
their understanding of content. He added some other positives of flipped classroom that include: 1) developing the role of teacher as a lecturer to become a guide and supervisor, and developing the role of student to become a researcher participating in the teaching and learning processes, 2) helping students' self- learning according to their abilities and individual differences, 3) providing students with excited educational environment, and enhancing high thinking skills such as critical thinking skills.

Alzain (2015 asserted that the flipped classroom is a modern technological solutionfor treating academic weaknesses of students and developing levels of their skills ofthinking. Al-Zain added that the flipped classroom strategy provides teacher withenough time to converse and discuss with students in classroom instead of memorization.Furthermore, through applying the model of flipped classroom the intellectualabilities of learners can grow up. By utilizing this method learners can develop theirknowledge in scientific, practical and behavioral sides. Dickenson (2016) addressed thatthe flipped classroom is considered as one of the active practices that enable thelearner to link between what is learned and his/her personal life and experiences. Insuch process, learner will be able to link what he/she learns with his/her intellectualbehaviors, until it becomes a part of his/her personality.

One of the key advantages of the Flipped Classroom is that it allows students to move through content and learn at their own individual pace. Students are given in effect the opportunity to 'pause' and 'rewind' the subject matter at their discretion, which would otherwise not be possible in a traditional lecture setting. As such, if they have difficulties understanding what the instructor is saying or if they are struggling with the fast pace of the course, they can revisit the video lecture or certain parts of it, as many times as they desire, until they are able to comprehend the topics being covered to their satisfaction irrespective of the gender. This is an important pedagogical consideration for International students for whom English is their second language. The use of the Flipped Classroom can help 'level the playing field'and make a significant impact on their ability to overcome language barriers critical to their learning and academic success (Fulton, 2012).

Academic performance has many different measures, besides a student's final grade. It is entirely possible that the overall effectiveness of the Flipped Classroom lies in the fact that it promotes higher order thinking, learning, and mastery of the subject matter on a consistent basis and throughout the course when compared to a traditional lecture format. In a traditional lecture, students usually have the tendency to study more heavily just prior to the midterm and final examinations. On the other hand, in the Flipped Classroom, students are strongly encouraged to study and learn the subject matter more regularly since they get tested on a weekly basis (i.e. by way of quizzes and in-class practice problem sets).In this study, the Flipped Classroom provided the students and the instructor with multiple educational advantages. From the students' perspective, it increased flexibility in learning because it allowed them to progress at their own pace (i.e. replay the lecture videos as many times as needed to better understand key concepts) and it increased free class time to practice and master applied skills (i.e. problem-solving activities). Additionally, students were permittedto further their understanding by critically thinking about, actively discussing and more importantly, peerteaching key concepts in a collaborative classroom setting.

In this manner, the Flipped Classroom made learning more manageable for students by taking difficult tasks and complex ideas and making them more understandable and accessible.

From the instructor's perspective, this setting made it easy to engage students and empower them to become active participants in their own learning. The Flipped Classroom not only permitted the instructor to provide the students with a wider breath and deeper understanding of the material covered but having more collaborative activities take place during class. Finally, the Flipped Classroom allowed the instructor to gain advanced, realtime insight into how students learn and quickly identify and better address curriculum content the students found to be most challenging. This insight can be used to better inform decisions with regard to effective curriculum organization, structuring and delivery of future classes (Kohn, 2011).

\section{Future directions}

Creating an effective and sustainable learning environment requires constant monitoring and timely adjustments. On the basis of the feedback provided to the research team by our students, we have identified several areas that require further improvement. First, the video lectures need to be significantly modified and a different, more user-friendly recording platform needs to be seriously considered. Second, the videos should be broken down into multiple, shorter video file segments (i.e. 2-3 videos of 20 to 30 minutes length each) so that students are able to give their undivided attention and fully concentrate on the content presented in one sitting. Additionally, the shorter videos will permit students to more easily pause and return to their video as well as allow them to watch each section at different times of the week, depending on their schedule. Third, the audio quality of the videos needs to be dramatically improved by making every effort to remove/eliminate the background noise. Fourth, an online forum needs to be created so as to permit the instructor to directly communicate with the students and address any pertinent questions in a timely manner prior to attending the actual class. Finally, administrative barriers need to be removed and more autonomy afforded to the instructor in order to ensure the 
timely release of the videos to the students.

\section{Purpose of the Study}

The purpose of this study was to assess the problems andexamine the effect of using flipped classroom strategy on teaching students in Nigerian Educational system. The study also intends to examine possible effects of flipped classroom on gender and their performance. The outcome of this effort will be used to suggest steps that can enhance and improve Students' performance in Nigerian Educational System.

\section{Research Hypotheses}

The following null hypotheses were generated and tested;

1. There is no significant difference between the pretest mean scores of subjects exposed to the flipped classroom strategy and conventional strategy

2. There is no significant difference between the posttest mean scores of students exposed to the flipped classroom strategy and conventional strategy.

3. There is no significant difference between the posttest mean scores of male students exposed to the flipped classroom strategy and conventional strategy

4. There is no significant difference between the posttest mean scores of female students exposed to the flipped classroom strategy and conventional strategy

\section{Methodology}

The study was a quasi-experimental pre-test, post-test, control group design. The pre-test was to establish the knowledge base line of the students that was used for the study while the post-test will measure the level of academic performance of the students after treatment. The design of the study is represented as follows: Experimental Group $=0_{1} \mathrm{X}_{1} 0_{2}$ and Control Group $=0_{3} \mathrm{X}_{2} \mathrm{O}_{4}$

Where $0_{1}, 0_{3}$, represent pre-test. $X_{1}=$ Flipped classroom strategy, $X_{2}=$ Conventional method. Also, $0_{2}, 0_{4}$, represent post-test.The target population for this study was made up of all the public Junior Secondary School II Basic Science students in Ekiti State.The sample for this study comprised 120 junior secondary school II Basic Science students selected from the three senatorial districts in Ekiti state using the multistage sampling technique. The first stage involved the selection of three local government areas across the three senatorial districts through random sampling technique. The second stage also involved selection of one school from each local government area through random sampling technique, while the next stage involved the selection of sixty (40) students from each of the sampled schools using stratified random sampling technique to ensure gender equality. Intact classes were used in each of the sampled schools.The instrument that was used for this study is Basic Science Achievement Test (BSAT). It is a self-designed instrument. Section A of the BSAT consisted of information on bio-data of the respondents while Section B consisted of 40 multiple-choice items that covers all the content of the chosen topics used as achievement test.

\section{Results}

H1: There is no significant difference between the pretest mean scores of students exposed to flipped classroom strategy and conventional strategy.

In testing this hypothesis, the mean total scores and standard error obtained from the pretest mean scores of students exposed to flipped classroom strategy and conventional strategy were subjected to t-test analysis at 0.05 level of significance.

Table 1: The t-test showing the pretest mean scores of students exposed to flipped classroom strategy and conventional strategy.

\begin{tabular}{|l|l|l|l|l|l|l|l|}
\hline Group & $\mathrm{N}$ & Mean & SD & df & t-cal & t-table & Result \\
\hline Flipped strategy & 60 & 34.57 & 2.35 & & & & \\
Conventional strategy & 60 & 20.57 & 1.58 & 118 & 28.31 & 1.96 & Significant at $\mathrm{p}<0.05$ \\
\hline
\end{tabular}

Table 1 shows that the mean score of students exposed to flipped classroom strategy is 34.57 with standard deviation of 2.35 , while the mean score of students exposed to conventional method is 20.57 with standard deviation of 1.58 . The $t$-calculated is 28.31 while the $t$-table is 1.96 . Thus the $t$-calculated is greater than the $t-$ table value; therefore, the null hypothesis is rejected.

H2: There is no significant difference between the posttest mean scores of students exposed to flipped classroom strategy and conventional strategy

In testing this hypothesis, the mean total scores and standard errors obtained from posttest mean scores of students exposed to flipped classroom strategy and conventional strategy were subjected to t-test analysis at 0.05 level of significance. 
Table 2: the t-test showing the posttest mean scores of students exposed to reciprocal instructional strategy and conventional strategy.

\begin{tabular}{|l|l|l|l|l|l|l|l|}
\hline Group & N & Mean & SD & df & t-cal & t-tab & Result \\
\hline Flipped strategy & 60 & 11.46 & 3.71 & & & & \\
Conventional strategy & 60 & 7.66 & 2.85 & 118 & 14.21 & 1.96 & Significant at $\mathrm{p}<0.05$ \\
\hline
\end{tabular}

Table 2 shows that the mean score of students exposed to flipped classroom strategy is 11.46 with standard deviation of 3.71 , while the mean score of students exposed to conventional method is 7.66 with standard deviation of 2.85. The $\mathrm{t}$-calculated is 14.21 while the table value is 1.96 . Thus, the $\mathrm{t}$-calculated is greater than $\mathrm{t}-$ table value, and therefore, the null-hypothesis is rejected. This implies that there is a significant difference between posttest means scores of students exposed to reciprocal instructional strategy and conventional strategy H3: There is no significant difference between the posttest mean scores of male students exposed to flipped classroom strategy and conventional strategy

In testing this hypothesis, the mean total score and standard error obtained from the posttest mean scores of male students exposed to flipped classroom strategy and conventional strategy were subjected to t-test analysis at 0.05 level of significance.

Table 3: The t-test showing the posttest mean scores of male students exposed to flipped classroom strategy and conventional strategy.

\begin{tabular}{|l|l|l|l|l|l|l|l|}
\hline Group & N & Mean & SD & df & t-cal & t-table & result \\
\hline Flipped strategy & 30 & 2.64 & 1.49 & & & & Not Significant at \\
Conventional strategy & 30 & 2.48 & 1.33 & 58 & 0.87 & 1.96 & $\mathrm{p}<0.05$ \\
\hline
\end{tabular}

Table 3 shows that the mean score of male students exposed to flipped classroom strategy is 2.64 with standard deviation of 1.49, while the mean score of male students exposed to conventional method is 2.48 with standard deviation of 1.33 . The t-calculated is 0.87 while the t-table is 1.96 . Thus the $t$-calculated is less than the t-table value; therefore, the null hypothesis is not rejected. This implies that there is no significant difference between the posttest means scores of male students exposed to flipped classroom strategy and conventional strategy

H4: There is no significant difference between the posttest mean scores of female students exposed to flipped classroom strategy and conventional strategy

In testing this hypothesis, the mean total score and standard error obtained from the posttest mean scores of female students exposed to flipped classroom and conventional strategy were subjected to t-test analysis at 0.05 level of significance

Table 4: The t-test showing the posttest mean scores female students exposed to flipped classroom strategy and conventional strategy

\begin{tabular}{|l|l|l|l|l|l|l|l|}
\hline Group & N & Mean & SD & df & t-cal & t-table & result \\
\hline Flipped Strategy & 30 & 29.74 & 2.80 & & & & Not Significant at \\
Conventional strategy & 30 & 27.54 & 2.84 & 58 & 1.47 & 1.96 & $\mathrm{p}<0.05$ \\
\hline
\end{tabular}

Table 4 shows that the mean score of female students exposed to flipped classroom strategy is 29.74 with standard deviation of 2.80, while the mean score of female students exposed to conventional method is 27.54 with standard deviation of 2.84 . The t-calculated is 1.47 while the t-table is 1.96 . Thus, the t-calculated is less than the t-table value; therefore, the null hypothesis is not rejected. This implies that there is no significant difference between the posttest means scores of female students exposed to flipped strategy and conventional strategies.

\section{Discussion}

The finding of the study revealed in hypothesis 1 that there is significant difference between the pretest mean scores of students exposed to flipped classroom strategy and conventional strategy. The study also revealed in hypothesis 2 that there is a significant difference between the posttest means scores of students exposed to flipped instruction and conventional strategy. This is in accordance to the submission of (Abey, 2015) who found out from his studies that students feel self-effective when they participate actively in spreading knowledge unlike what they have previously been when receiving knowledge from the instructor through traditional teaching.In addition, flipped classrooms contribute to encouraging and improving skills in the domains of application, analysis, synthesis and evaluation which are all mental skills and processes not covered by the traditional curricula. It also contributes to what is known as ownership for learning. Therefore, increases and improve students 'comprehension, develop self-regulatoryand monitoring skills, and achieve overall improvement in motivation, hence affects the performance of students positively. It was therefore found from the study that students exposed to flipped classroom instruction performed better than those exposed to conventional method. The study also revealed in hypothesis 3 and 4 that there is no significant difference between the posttest mean scores of male and female students exposed to reciprocal instruction and conventional strategies. This was in accordance to the study of(Jarvenoja, 2010) who shared the view that there is no sex difference in general 
intelligence. This is an indication that gender has no significant contribution because male and female students exposed to the same treatment have nearly same scores in the test.

\section{Conclusion}

Based on the findings of this study, it was found that flipped classroom strategy was more effective in teaching Basic Science than the conventional method. The flipped classroom strategyallows students to move through content and learn at their own individual pace. Students are given in effect the opportunity to 'pause' and 'rewind' the subject matter at their discretion, which would otherwise not be possible in a traditional lecture setting. As such, if they have difficulties understanding what the instructor is saying or if they are struggling with the fast pace of the course, they can revisit the video lecture or certain parts of it, as many times as they desire, until they are able to comprehend the topics being covered to their satisfaction irrespective of the gender.Therefore has the potency of producing higher students' performance in Nigerian educational system. It was also discovered that sex does not play any significant role in students' performance. Male and female students exposed to same treatment did not differ significantly in their performance.

\section{Recommendations.}

Based on the findings, the researcher considers the following recommendations necessary:

1. Basic Science teachers should adopt flipped classroom strategy in classrooms to enable students participate actively and utilize multimedia to arouse their interest and improve performance.

2. Government should provide enabling environment for teachers and making the school conducive for participatory studentship.

3. The curriculum planners should introduce some multimedia and internet packages into the methodologies of teaching sciences to update teachers' knowledge on the application of the flipped classroom strategy.

4. The videos should be broken down into multiple, shortervideo file segments (i.e. $2-3$ videos of 20 to 30 minutes length each) so that students are able to give their undivided attention and fully concentrate on the content presented in one sitting.

\section{References}

Abey, S. L.(2015). Motivation and cognitive load in flipped classroom: definition, rational and a call for research. Higher Education Research \& development, 34(1), 1-14. https://doi.org/10.1080/07294360.2014.934336

Abimbola, I. O. (2013). The one hundred and twenty-third (123rd) inaugural lecture: The misunderstood word in science: towards a technology of perfect understanding for all. Ilorin: University of Ilorin.

Adu, E.O \& Adeyanju,H.(2013): Home and school factorsas determinant of students' achievement in seniorsecondary school economics in Botswana ARPN, Journal of Science and Technology, 3(2): 219-221.

Alzain, H. (2015). The impact of the application of the concept of the inverted row in the academic achievement of students in the Faculty of Education Princess Nora bint Abdul

Rahman University, Riyadh. The International Journal of Educational specialist, 4(1), 171-186.

Bergmann, J., \& Sams, A. (2012). Flip your classroom: Reach every student in every class every day. Eugene, OR: International Society for Technology in Education.

Bishop, J. L. (2013). The Flipped Classroom: A survey of Research. ATLANTA, Paper ID\#6219@ American Society for Engineering Education

Collins, A., and Halverson, R. (2009). Rethinking Education in the Age of Technology. New York: Teachers College Press.

DeLozier, S. J., \& Rhodes, M. G. (2017). Flipped classrooms: A review of key ideas and recommendations for practice. Educational Psychology Review, 29(1), 141e151. https://doi.org/10.1007/s10648-015-9356-9

Deslauriers, L.(2011). Learning and retention of quantum concepts with different teaching methods. Phys Rev Spec Topics Phys Educ Res.7:1-6.

Dickenson, P. (2016). The flipped classroom in a hybrid teacher education course: Teachers' self-efficacy and instructors' practices. Journal of Research in Innovative Teaching. 9(1), 78-89.

Dike, S. (2014). Opening Remarks Presented at the Train-the -Trainers Workshop on the Use of the Revised 9Year Basic Education Curriculum held at Rock view Hotel, Abuja Nigeria, 5-9th August, 2014.

Fulton, K.(2012). Upside down and inside out: flip your classroom to improve students' learning. Learn Lead Technol. 39(8): 2-7.

Harris, B.,.(2016). Flipped Classroom: Another Tool for Your Pedagogy Tool Box. Developments in Business Simulation and Experiential Learning, 1(43), 325-333.

Jarvenoja, H. (2010). Socially shared regulation of motivation and emotion in collaborative learning: Faculty of Education, University of OULU.

Kohn, A.(2011). Beware of the standards, not just the tests. Educ Week.;38:52. 
Leo, J. and Puzio, K. (2016). Flipped instruction in a high school science classroom. Journal of Science Education and Technology, 25(5): 775 - 781.

Mok, H. N. (2014). Teaching Tip: The flipped classroom. Journal of Information Systems Education, 25(1).

Panich, P. (2013). Flipped classroom. Bangkok, Thailand: S R Printing Mass Product. [in Thai]

Songhao. (2011). Evolution from Collaborative Learning to Symbiotic E-Learning: Creative of New E-Learning Environment for Knowledge society. US-China Education Review, 8(1), 46-53.

Strayer, J.F.(2012). How learning in an inverted classroom influences cooperation, innovation and task orientation. Learn Environ Res;15(2):71-93.

Strohmyer, D. (2016). Student perceptions of flipped learning in a high school math classroom. Ph. D. Dissertations, Walden University, Minnesota. Retrieved on 1st, September,

2017, from: http://scholarworks.waldenu.edu/cgi/viewcontent.cgi?article=3281\&context=Dissertations

Yilmaz, R. (2017). Exploring the role of eelearning readiness on student satisfaction and motivation in flipped classroom. Computers in Human Behavior, 70, 251e260. https://doi.org/10.1016/j.chb.2016.12.085.

Zhonggen, Y. and Guifang, W. (2016). Academic achievements and satisfaction of the clicker-aided flipped business English writing class. Educational Technology \& Society, 19(2): 298 - 312. 